\title{
Effect of EpCAM, CD44, CD133 and CD166 expression on patient survival in tumours of the ampulla of Vater
}

\author{
Salvatore Piscuoglio, ${ }^{1}$ Frank S Lehmann, ${ }^{2}$ Inti Zlobec, ${ }^{1}$ Luigi Tornillo, ${ }^{1}$ \\ Wolfgang Dietmaier, ${ }^{3}$ Arndt Hartmann, ${ }^{4}$ Peter H Wünsch, ${ }^{5}$ Fausto Sessa, ${ }^{6}$ \\ Petra Rümmele, ${ }^{3}$ Daniel Baumhoer, ${ }^{1}$ Luigi M Terracciano ${ }^{1}$
}

\begin{abstract}
- Additional materials are published online only. To view these files please visit the journal online (http://jcp.bmj. com/content/65/2.toc).

${ }^{1}$ Institute of Pathology, University Hospital of Basel, Basel, Switzerland

${ }^{2}$ Department of Gastroenterology and Hepatology, University Hospital of Basel, Basel, Switzerland ${ }^{3}$ Department of Pathology, University Hospital of Regensburg, Regensburg, Germany

${ }^{4}$ University Hospital of Erlangen, Erlangen, Germany ${ }^{5}$ Municipal Hospital of Nürnberg, Nürnberg, Germany

${ }^{6}$ Anatomic Pathology Unit, University of Insubria, Varese, Italy
\end{abstract}

\section{Correspondence to}

Prof Luigi M Terracciano, Institute of Pathology, University Hospital of Basel,

Schönbeinstrasse 40, 4003

Basel, Switzerland;

Iterracciano@uhbs.ch

Salvatore Piscuoglio and Frank S Lehmann are equally contributed to this work.

Accepted 13 July 2011 Published Online First 30 November 2011

\section{ABSTRACT}

Background Carcinomas of the Vaterian system are rare and presumably arise from pre-existing adenomas. According to the cancer stem cell (CSC) hypothesis, only a small subset of tumor cells has the ability to initiate and develop tumor growth. In colorectal cancer, CD44, CD133, CD166 and EpCAM have been proposed to represent CSC marker proteins and their expression has been shown to correlate with patient survival.

Aims To evaluate a potential role of these CSC proteins in tumors of the ampulla of Vater, we investigated their expression in 175 carcinoma, 111 adenoma and 152 normal mucosa specimens arranged in a Tissue Microarray format.

\section{Materials and methods Membranous}

immunoreactivity for each protein marker was scored semi-quantitatively by evaluating the number of positive tumor cells over the total number of tumor cells. Median protein expression levels were used as cut-off scores to define protein marker positivity. Clinical data including survival time were obtained by retrospective analysis of medical records, tumor registries or direct contact.

Results The expression of all evaluated marker proteins differed significantly between normal mucosa, adenoma and carcinoma samples. In all markers, we found a tendency towards more constant expression from normal to neoplastic tissue. EpCAM expression was significantly correlated with better patient survival. The increased expression of CD44s, CD166 and CD133 from normal mucosa samples to adenoma and carcinoma was linked to tumor progression. However, there was no statistically significant correlation with survival.

Conclusion Our findings indicate, that in ampullary carcinomas, loss of expression of EpCAM may be linked to a more aggressive tumor phenotype.

\section{INTRODUCTION}

The ampulla of Vater combines the terminal and common segment of the bile and pancreatic duct before they enter the duodenum. ${ }^{1}$ Carcinomas originating from this complex anatomical unit are uncommon and have an incidence of approximately four to six cases per million population. ${ }^{2}{ }^{3}$ Carcinomas of the papilla of Vater, defined as junction of the biliary, and pancreatic ducts within the duodenum account for $6 \%-20 \%$ of all peripancreatic tumours ${ }^{4}$ and represent $10 \%-50 \%$ of all cancers resected by pancreaticoduodenectomy. ${ }^{5}$ They can be sited in the ampulloduodenal part of the papilla of Vater, which is lined by intestinal mucosa. They also can develop in deeper parts of the ampulla, which are lined by pancreaticobiliary duct mucosa. Clinically, tumours of the ampulla of Vater are rapidly detected due to biliary outflow obstruction. ${ }^{6} 7$ Early symptoms as well as differences in tumour biology are held responsible for their favourable clinical outcome (median survival $30-50$ months, 5 -year survival rate $21 \%-64 \%$ ). ${ }^{89}$ Histologically, intestinal, pancreaticobiliary, intestinal-mucinous, invasive papillary and poorly differentiated subtypes can be distinguished. ${ }^{10}$ The subtypes differ in several clinical and histological aspects including cell type-specific markers, oncogene expression, modes of tumour spread as well as extent and interaction with the extracellular matrix. ${ }^{11}$ Most authors agree that local spread of the tumour ( $T$ stage) is the only significant and independent prognostic factor for this cancer, whereas the predictive value of tumour grade and lymph node metastases is still debated. ${ }^{12}{ }^{13}$ More recent research data suggest that the prognosis of ampullary cancer may be related to the histological differentiation in intestinal or pancreatobiliary types. ${ }^{14}$ In the last years, several molecular markers have been proposed as additional prognostic factors. However, most of these studies have yielded conflicting results and have not been still validated by other reports. ${ }^{15-19}$ Several sources of discrepancy between different reports have been acknowledged mainly due to non-standardised assays often performed on underpowered patient samples that are too small to enable meaningful conclusions to be drawn. Therefore, there is undoubtedly a need for additional prognostic markers for such neoplasia. Recent findings support the concept that cells with the properties of stem cells are integral to the development and perpetuation of several forms of human cancer. ${ }^{20} 21$ Cancer stem cells (CSCs) have low replicative ability, multipotency and resistance to apoptosis and are responsible for tumour development. ${ }^{22}$ In the different types of digestive tumours, different sets of markers have emerged as the most useful for the identification of CSC. In particular, in intestinal as well as in pancreatic cancer, some markers including CD44, EpCAM, CD166 and CD133 have been indicated as possible CSCs markers. Furthermore, in colorectal cancer, we have shown that their expression inversely correlated with patient survival. ${ }^{23}$ However, conflicting results have been 
reported about the role of some putative CSC markers in gastrointestinal tract tumours. In particular, contradictory findings have been reported about the association of CD44, in particular of its v6 splicing variant, and tumour progression. $^{24-26}$ Furthermore, while CD133 molecule was initially identified as a reliable CSC marker in human colorectal cancers, ${ }^{27} 28$ a subsequent study has shown that in both mouse and human colorectal cancers, CD133 expression is not restricted to rare cell subsets, but it is detectable in a large majority of tumour cells, irrespective of their tumourigenicity. ${ }^{29}$ Because of the lacking studies dealing with CSC markers in ampullary tumours, the aim of this study was to elucidate the expression and the prognostic role of CD133, CD166, CD44s, EpCAM expression in ampullary tumours by using a tissue microarray (TMA) including 175 carcinoma, 111 adenoma and 152 normal mucosa specimens of the papilla of Vater.

\section{MATERIAL AND METHODS Ethics}

The study has been approved by the institutional review board of the Department of Pathology, University of Basel, Switzerland. All the analyses were performed according to the ethical standards required by each local ethic committee.

\section{Patients' characteristics and tissue samples}

Patients' characteristics have been previously described by our study group. ${ }^{30}{ }^{31}$ Briefly, the files of the Institute of Pathology, University Hospital Basel (Switzerland), the Institute of Pathology, University of Regensburg (Germany), the Institute of Pathology Nuernberg and the Anatomic Pathology Unit, Department of Human Morphology, University of Insubria, Varese (Italy), were searched for adenomas or carcinomas of the ampulla of Vater over the period from 1985 to 2005. In total, 175 carcinoma, 111 adenoma and 152 normal mucosa samples were retrieved. Sufficient paraffin-embedded tissue for TMA construction was available in all cases. The male-to-female ratio was 3:2; mean age at diagnosis was 63 years (range 15-81 years). To our knowledge, no case was associated with Familial adenomatous polyposis (FAP).

\section{TMA construction}

TMAs were constructed from formalin-fixed and paraffinembedded specimens using a custom-built instrument (Beecher Instruments, Silver Spring, Maryland, USA) as previously described. $^{30}{ }^{31}$ Briefly, H\&E-stained sections were obtained from each selected primary block (donor block) to define representative tissue regions. Core biopsies ( $0.6 \mathrm{~mm}$ cylinders) were taken from the selected tissue regions and then transferred to a paraffin recipient block. The resulting TMA was cut into $4 \mu \mathrm{m}$ sections, which were used for immunohistochemistry. The number of punches per patient ranged from one to three for both normal tissue and carcinoma and from one to five for adenomas. If more than one punches was obtained, the additional punches were taken from different representative blocks.

\section{Histology and immunophenotyping}

All tumours were classified according to the guidelines of the Armed Forces Institute of Pathology using only H\&E stains. ${ }^{10}$ Mild dysplasia was designated as low-grade dysplasia, whereas moderate and severe dysplasia was considered as high-grade dysplasia. Carcinomas histologically indistinguishable from colorectal carcinomas were classified as intestinal types, whereas carcinomas showing a dense desmoplastic stroma surrounding small glands or solid nests of tumour cells were referred to as the pancreaticobiliary subtype. Invasive papillary carcinomas typically formed papillary and micropapillary structures in their invasive component and poorly differentiated adenocarcinomas lacked histologic features of glandular or other differentiation. Additionally, an intestinal-mucinous subtype, characterised by any mucinous differentiation, was defined.

For immunohistochemistry, sections were pre-treated with CC1 (Ventana Medical Systems, Tucson, Arizona, USA) and incubated with primary antibodies against CD133, CD44s, CD166 and EpCAM (table 1). Staining procedures were performed on a Benchmark immunohistochemistry staining system (Ventana Medical Systems) using iVIEW-DAB as chromogen.

Membranous immunoreactivity for each protein marker was scored semiquantitatively by evaluating the number of positive tumour cells over the total number of tumour cells. Scores were assigned using 5\% intervals and ranged from $0 \%$ to $100 \%$. All tissues were scored by an experienced pathologist (LT), blinded to clinicopathological information. To define interobserver agreement, all samples were examined independently by a second pathologist (DB).

\section{Statistical analysis}

Statistical correlations between categorical variables were tested using a $\chi^{2}$ or Fisher exact test, where appropriate. Differences in patient survival were demonstrated using the Kaplan-Meier method and analysed using the log-rank test in univariate analysis. All tests were two sided. $p$ Values $<0.05$ were considered statistically significant. Cut-off scores were selected by evaluating the receiver operating characteristic curves for each protein marker and the end-point survival. The point on the curve with the shortest distance to the coordinate $(0,1)$ was selected as the threshold value to classify cases as 'positive/ overexpressing' or 'negative/loss'. ${ }^{32}$ Analysis was performed using SAS V.9.1 (SAS Institute).

\section{RESULTS}

\section{Patients' characteristics and tissue samples}

Overall, 175 carcinoma, 111 adenoma and 152 normal mucosa samples were retrieved. In patients with carcinomas, we found 19 pT1 (11\%), 59 pT2 (34\%), 63 pT3 (36\%) and 13 pT4 (7\%) tumours as well as 17 G1 (10\%), 82 G2 (47\%) and 55 G3 (31\%) cases (no data concerning $\mathrm{T}$ stage and grading in 21 samples). Seventy-three $(42 \%)$ carcinoma patients were node positive and two (1\%) had haematogenous metastases at initial diagnosis.

Full clinical data including survival time were available in 133 patients with ampullary carcinoma (76\%). Patients were studied up to 164 months after operation. Median follow-up time was 36 months.

The histological classification of 175 ampullary carcinomas identified 85 intestinal types, 42 pancreaticobiliary types, 23 poorly differentiated adenocarcinomas, 16 intestinal-mucinous types and nine invasive papillary types.

Table 1 Primary antibodies against CD133, CD44, CD166 and EpCAM

\begin{tabular}{lll}
\hline Antibody & Dilution/detection & Pretreatment \\
\hline CD44 (Dako, DF1485) & $1: 50 / B O N D$ & BOND ER2 \\
CD133 (cell signalling, C24B9) & $1: 100 / B O N D$ & Steamer $120^{\circ}$ C, pH8 \\
CD166 (Novocastra, MOG/07) & $1: 200 / B O N D$ & BOND ER2 \\
EpCAM (Novocastra, VU-1D9) & $1: 200 / B O N D$ & BOND ER2 \\
\hline
\end{tabular}


Figure 1 Immunophenotyping in tissue samples from patients with ampullary carcinoma $(400 \times)$. (A) CD44. (B and C) CD133. (D and E) CD166. (F) EpCAM.
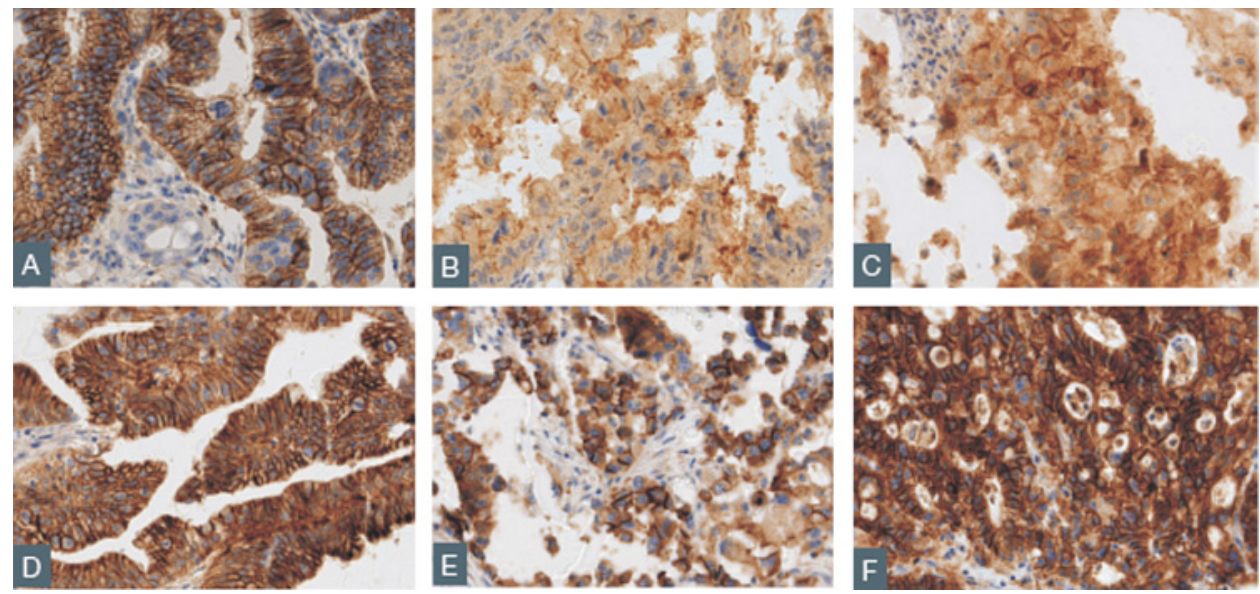

Histological grading was evaluable in 76 of 111 (68\%) adenomas and disclosed low-grade dysplasia in 57 of $76(75 \%)$ and high-grade dysplasia in 19 of 76 (25\%) cases. All adenomas demonstrated tubular or tubulovillous architecture. Seventyeight of 111 (70\%) adenoma samples were derived from patients with coexisting carcinoma.

\section{Immunophenotyping}

Tissue samples of ampullary carcinoma patients expressing CD44, CD133, CD166 and EpCAM are shown in figure 1. Moreover, in table 2, the distribution of the different biomarkers across different diagnostic categories is shown.

The expression of all marker proteins differed significantly between carcinoma, adenoma and normal mucosa samples (table 3).

We have also evaluated the positivity in the two principal histologic types (intestinal type vs pancreatobiliary type). EpCAM was significantly more expressed in intestinal type (table 4).

We have tried also to evaluate if there is some difference between adenomas without coexisting carcinoma and adenomas without coexisting carcinomas. Only CD44 was significantly more expressed in adenomas with coexisting carcinomas $(\mathrm{p}=0.043)$.

No difference was found between low-grade and high-grade adenomas (data not shown).

\section{Survival}

Five-year survival (95\% CI) was 45.2 (34 to 56) in EpCAMpositive versus 28.2 (11 to 48 ) in EpCAM-negative patients $(p<0.05)$. EpCAM was not an independent prognostic factor after adjusting for $\mathrm{pT}$ and $\mathrm{pN}$ stages. Survival curves of both patient groups using the Kaplan-Meier method are demonstrated in figure 2 .

\section{DISCUSSION}

Tumours of the papilla of Vater are a relatively rare neoplastic entity that came into focus in recent years. Significant overlap exists in phenotypic and molecular characteristics between ampullary and colorectal carcinomas. As in colorectal cancer, the development of ampullary carcinoma from adenomas as precancerous lesions has been well documented, and studies investigating molecular alterations associated with the proposed adenoma-carcinoma sequence have been also performed, including our group. ${ }^{33}$ However, still missing is a comprehensive analysis of the expression of putative CSC markers in very large groups of patients, amenable to detailed statistical analysis. Moreover, the prognostic significance of the co-expression of multiple CSC markers within the same tumour has not been evaluated so far.

This is the first systematic study assessing the prognostic value of four CSC markers, namely EpCAM, CD44, CD133 and CD166, in a large series of patients with ampullary tumours.

Table 2 Distribution of biomarkers between different diagnostic categories

\begin{tabular}{|c|c|c|c|c|c|c|c|c|}
\hline & \multicolumn{7}{|c|}{ Number of cases within each expression category } & \multirow[b]{2}{*}{ Sum } \\
\hline & $0 \%$ & $1 \%-5 \%$ & $6 \%-20 \%$ & $21 \%-40 \%$ & $41 \%-60 \%$ & $61 \%-80 \%$ & $81 \%-100 \%$ & \\
\hline \multicolumn{9}{|l|}{ Normal } \\
\hline CD133 & 9 & 63 & 30 & 0 & 1 & 1 & 0 & 104 \\
\hline CD44 & 67 & 20 & 8 & 7 & 3 & 6 & 4 & 115 \\
\hline CD166 & 81 & 5 & 6 & 3 & 6 & 1 & 13 & 115 \\
\hline EpCAM & 7 & 1 & 0 & 0 & 2 & 2 & 89 & 101 \\
\hline \multicolumn{9}{|l|}{ Adenoma } \\
\hline CD133 & 10 & 61 & 14 & 0 & 0 & 0 & 0 & 85 \\
\hline CD44 & 25 & 13 & 17 & 5 & 3 & 14 & 12 & 89 \\
\hline CD166 & 58 & 9 & 5 & 1 & 4 & 3 & 6 & 86 \\
\hline ЕрСАM & 0 & 0 & 0 & 1 & 2 & 1 & 89 & 93 \\
\hline \multicolumn{9}{|l|}{ Cancer } \\
\hline CD133 & 16 & 83 & 45 & 6 & 1 & 0 & 0 & 151 \\
\hline CD44 & 38 & 15 & 27 & 19 & 9 & 18 & 18 & 144 \\
\hline CD166 & 84 & 19 & 14 & 9 & 5 & 7 & 10 & 148 \\
\hline ЕрСАМ & 2 & 0 & 1 & 1 & 3 & 3 & 136 & 146 \\
\hline
\end{tabular}


Table 3 Expression of all evaluated marker proteins in normal mucosa, adenoma and carcinoma samples

\begin{tabular}{|c|c|c|c|c|}
\hline & Normal & Adenoma & Carcinoma & $\bar{p}$ Value \\
\hline $\mathrm{CD} 44+(>5 \%)$ & $29 / 118(24.6 \%)$ & $52 / 90(57.8 \%)$ & $91 / 145(62.8 \%)$ & $<0.001$ \\
\hline $\mathrm{CD} 133+(>5 \%)$ & $30 / 104(28.9 \%)$ & $11 / 74(12.9 \%)$ & $44 / 151(29.1 \%)$ & 0.012 \\
\hline CD166+ $(>0 \%)$ & $34 / 120(28.3 \%)$ & $28 / 87(32.2 \%)$ & $64 / 151$ (42.4\%) & 0.044 \\
\hline ЕрСАМ + $+100 \%)$ & $89 / 104(85.6 \%)$ & $88 / 93(94.6 \%)$ & $115 / 145$ (79.3\%) & 0.005 \\
\hline
\end{tabular}

The overexpression of EpCAM was significantly correlated with better survival time. The increasing expression of CD44, CD166 and CD133 from normal mucosa samples to adenoma and carcinoma was linked to tumour progression. However, there was no statistically significant correlation with survival.

EpCAM is a glycosylated, $30-40 \mathrm{kDA}$ type I membrane protein, which is expressed in a variety of human epithelial tissue cancers, as well as in progenitor and stem cells. It is composed of an extracellular domain with epidermal growth factor and thyroglobulin repeat-like domains, a single transmembrane domain and a short 26 amino acid intracellular domain called EpICD. In normal cells, EpCAM is predominantly located in intercellular spaces, where epithelial cells form very tight junctions. Therefore, on normal epithelia, it is sequestered and may be much less accessible to antibodies than in cancer tissue, where it is homogeneously distributed on the cell surface. Furthermore, EpCAM is part of the signature of cancerpropagating cells in numerous solid tumours as well as in normal progenitor and stem cells. ${ }^{34}$

EpCAM was one of the first tumour-associated antigens identified in the late 1970s. Systematic analysis of EpCAM expression for intensity and frequency showed that EpCAM is expressed on essentially all human adenocarcinoma, on certain squamous cell carcinoma, on retinoblastoma and on hepatocellular carcinoma. ${ }^{35}$

Importantly, EpCAM is part of the signature of cancerpropagating cells in numerous solid tumours and of normal progenitor and stem cells. ${ }^{34}$ The controversial biological role of EpCAM has recently been discussed by van der Gun et al. ${ }^{36}$ It is of interest that EpCAM overexpression has been associated with both decreased and increased survival time. EpCAM exerts different effects on cell adhesion, either promoting or preventing metastasis. ${ }^{36}$ The correlation of EpCAM expression and poor survival has been described in several tumour types, including invasive breast cancer, ${ }^{37}$ urothelial carcinoma of the bladder, ${ }^{38}$ gallbladder carcinoma ${ }^{39} 40$ and squamous cell carcinoma of the oesophagus. ${ }^{41}$ In different tumours, studies on EpCAM-directed immunotherapeutic therapies are currently in clinical development. Therapeutic trials of monoclonal antibodies directed against EpCAM have shown that they may induce antibody-based cellular cytotoxicity by adhering to cytokines such as interleukin 2 or complement-based cytotoxicity by activating T cytotoxic cells. ${ }^{42} 43$

Table 4 Expression of evaluated markers in the two principal histologic subtypes of ampullary carcinoma

\begin{tabular}{llll}
\hline & Intestinal & Pancreatobiliary & p Value \\
\hline $\operatorname{CD} 44+(>5 \%)$ & $82 / 99(82.8 \%)$ & $33 / 41(80.5 \%)$ & 0.805 \\
$\operatorname{CD} 133+(>5 \%)$ & $27 / 88(30.7 \%)$ & $12 / 40(30.0 \%)$ & 0.938 \\
$\operatorname{CD} 166+(>0 \%)$ & $73 / 97(76.8 \%)$ & $32 / 44(72.7 \%)$ & 0.672 \\
EpCAM+ $(100 \%)$ & $68 / 75(90.7 \%)$ & $25 / 33(75.8 \%)$ & $\mathbf{0 . 0 3 9}$ \\
\hline
\end{tabular}

\footnotetext{
The bold value means that EpCAM overexpression is statistically significant.
}

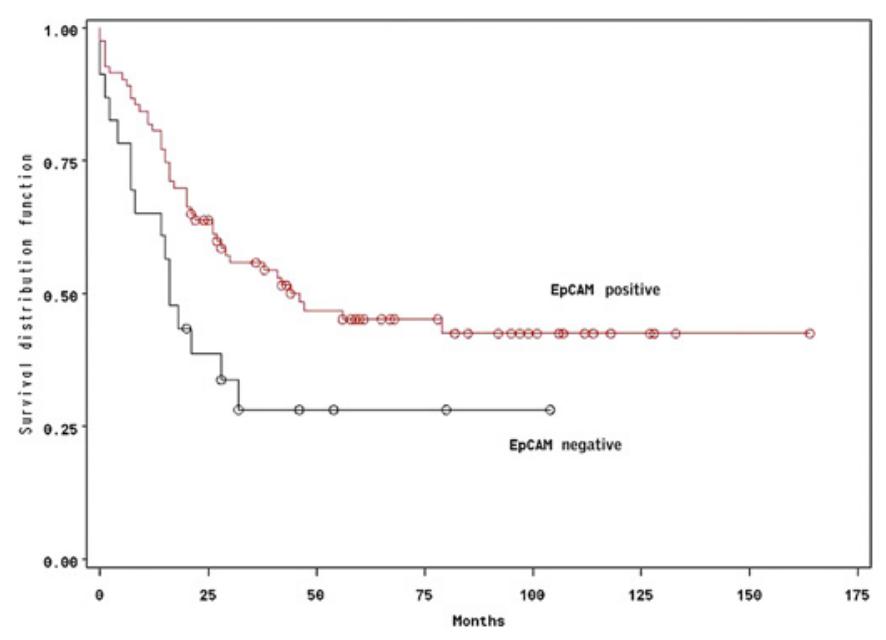

Figure 2 Survival of patients with EpCAM-positive and -negative ampullary carcinoma using the Kaplan-Meier method.

Previous studies have yielded conflicting results regarding EpCAM expression and survival in ampullary carcinoma. By Scheunemann et al, ${ }^{44}$ EpCAM expression has been associated with poorer survival in tumours of the papilla of Vater. This study, however, was mainly focused on the frequency and prognostic impact of minimal tumour cell spread in lymph nodes classified as 'tumour free' in routine histopathologic evaluation, and EpCAM expression in primary tumours was not analysed.

More recently, Fong et al ${ }^{45}$ were unable to prove a prognostic value of EpCAM overexpression in pancreatic and ampullary carcinoma. In contrast, in our study, we showed that decreased EpCAM membranous expression significantly correlated with biological features of aggressive tumour behaviour. Our study therefore suggests that diminished EpCAM expression is related to tumour invasiveness and progression and it is linked to a more aggressive tumour phenotype. This could also be confirmed by the more frequent expression of EpCAM in intestinal-type than in pancreatobiliary-type tumours. Intestinal-type tumours are in fact associated with a better prognosis. ${ }^{14}$

Several reasons for the discrepancies between our results and previous studies can be hypothesised including differences in sample size (power for detecting prognostic differences), methodology (TMA vs whole tissue sections), different clones of antibody and, most importantly, the choice of cut-off scores for the definition of positive staining or staining intensity.

EpCAM is intensely used as a therapeutic target for antibodybased approaches. Future development of EpCAM-directed therapeutics may profit from newly identified functions of EpCAM as mitogenic signal transducer in various ways. An important insight is that EpCAM is apparently needed to maintain distinct cancer cell attributes ${ }^{46}$ and, potentially, the CSC phenotype as well. This function can reduce the risk of immune escape by loss of EpCAM target expression from cancer cells. EpCAM-directed therapies may be selective for those cancer cells with the strongest negative impact on prognosis and for cancer-propagating subsets of malignant cells.

Discrepant results have also been reported regarding the effect of CD44 gene or protein and its splice variants on survival in tumour patients and it is an important receptor that binds hyaluronan (HA). CD44 has previously been considered to be a marker of tumour invasiveness and metastasis. Only recently, it has been described as putative colorectal CSC marker. 


\section{Take-home messages}

- CD44, CD133 and CD166 but not EpCAM immunohistochemical expression increased from normal mucosa to adenoma to carcinoma.

- EpCAM was more expressed in intestinal-type ampullary carcinoma.

- Loss of EDCAM may be linked to a more aggressive tumour phenotype.

- Loss of expression of EpCAM, but not of CD44, CD133 or CD166, is linked to poor survival.

However, $C D 44$ does not seem to belong to the group of genes, such as OCT4 and NANOG, that are central for maintaining stem cell characteristics. Nonetheless, two connections between $C D 44$ and genes that regulate stem cell characteristics have been described. First, CD44 is a target of the WNT pathway. Loss of adenomatous polyposis coli (APC) function leads to the constitutive activation of $\beta$ catenin, a constituent of the WNT signalling pathway. CD44s and CD44v6 expression is restricted to the intestinal crypts in non-transformed tissue, but both CD44 isoforms are strongly overexpressed in dysplastic crypts and adenomas in humans and mice with mutant APC $^{47}$ Second, HA-CD44 binding promotes protein kinase $\mathrm{C}$ (PKC) activation and this increases NANOG phosphorylation and translocation to the nucleus. Here, it associates with Drosha and an RNA helicase, p68, leading to the transcription of the oncogenic microRNA (miRNA) miR-21 and a reduction in the expression of the tumour suppressor programmed cell death 4 . These events initiate the upregulation of the inhibitor of apoptosis (IAP) proteins and multidrug resistant protein 1 (MDR1). CD44, in turn, associates with and stabilises MDR1 expression. ${ }^{48}$ This could be one mechanism through which CD44 contributes to stem cell resistance to chemotherapy, as MDR1 exports several drugs from cells.

In several gastrointestinal tumours, including colorectal cancer, ${ }^{23}$ stromal $^{49}$ as well as neuroendocrine tumours, ${ }^{50}$ loss of CD44 expression has been associated with disease progression and reduced survival. In our study, CD44 expression was more frequently associated with adenomas with coexisting carcinomas.

Our study is also the first to evaluate the prognostic impact of CD166 in ampullary carcinoma. We found an increasing expression of CD166 from normal tissue to carcinoma, suggesting that the increased expression of this marker might be linked to tumour progression. Our data are supported by a recent study in colorectal cancer patients, where a similar increasing expression of CD166 from normal to neoplastic tissue has been described by Weichert et al. ${ }^{51}$

We speculate that our findings of decreased rather than increased expression of membranous EpCAM expression and its association with features of tumour progression are mainly a consequence of its cell adhesion function.

In colorectal cancer, Kojima et $a l^{52}$ and Horst et $a l^{53}$ reported a significant correlation of increased CD133 expression and poor clinical outcome. In contrast, in a study on non-small-cell lung cancer, CD133 expression was not a prognostic factor for survival. ${ }^{54}$ Consistent with the latter study, we found no significant impact of CD133 on survival in our series of ampullary cancer patients.
In summary, we have provided evidence that in ampullary carcinoma, loss of expression of EpCAM, but not of CD44, $\mathrm{CD} 133$ or CD166, is linked to poor survival.

\section{Competing interests None.}

Patient consent If yes, who signed it?

Ethics approval Ethische Kommission Beider Basel.

Contributors SP, FSL and DB chose the antibodies, collected the data, wrote the introduction and the discussion. LMT and DB performed the immunohistochemical evaluation. SP performed the immunohistochemical staining. IZ performed the statistical evaluation. LT, LMT, PR, FS, PHW and WD revised and reclassified the tumours. LMT and LT revised the manuscript.

Provenance and peer review Not commissioned; externally peer reviewed.

\section{REFERENCES}

1. Allescher HD. Papilla of Vater: structure and function. Endoscopy 1989;21(Suppl 1):324-9.

2. Neoptolemos JP, Talbot IC, Carr-Locke DL, et al. Treatment and outcome in 52 consecutive cases of ampullary carcinoma. Br J Surg 1987;74:957-61.

3. Goodman MT, Yamamoto J. Descriptive study of gallbladder, extrahepatic bile duct, and ampullary cancers in the United States, 1997-2002. Cancer Causes Control 2007; 18:415-22.

4. Brennan MF. Surgical management of peripancreatic cancer. In: Bland KL, Karakoukis CP, Copeland EM, eds. Atlas of Surgical Oncology. Philadelphia, PA: WB Saunders Company, 1995:473.

5. Fisher HP, Zhou H. Pathogenesis of carcinoma of the papilla of Vater. $J$ Hepatobiliary Pancreat Surg 2004;11:301-9.

6. Benhamiche AM, Jouve JL, Manfredi S, et al. Cancer of the ampulla of Vater: results of a 20-year population-based study. Eur J Gastroenterol Hepatol 2000;12:75-9.

7. Albores-Saavedra J, Schwartz AM, Batich K, et al. Cancers of the ampulla of Vater: demographics, morphology, and survival based on 5,625 cases from the SEER program. J Surg Oncol 2009;100:598-605.

8. Wright NH, Howe JR, Rossini FP, et al. Tumours of the small intestine. In: Hamilton SR, Aaltonen LA, eds. World Health Organization Classification of Tumours: Pathology and Genetics of Tumours of the Digestive System. IARC, 2000:69-92.

9. Di Giorgio A, Alfieri S, Rotondi F, et al. Pancreatoduodenectomy for tumors of Vater's ampulla: report on 94 consecutive patients. World J Surg 2005;29:513-18.

10. Albores-Saavedra J, Henson DE, Klimstra DS. Tumors of the Gallbladder, Extrahepatic Bile Ducts, and Ampulla of Vater. Washington, DC: Armed Forces Institute of Pathology, 2000:259-316.

11. Schirmacher $\mathbf{P}$, Büchler MW. Ampullary adenocarcinoma-differentiation matters BMC Cancer. Lyon, 2008;8:251.

12. Talamini MA, Moesinger RC, Pitt HA, et al. Adenocarcinoma of the ampulla of Vater. A 28-year experience. Ann Surg 1997;225:590-9.

13. Dorandeu A, Raoul JL, Siriser F, et al. Carcinoma of the ampulla of Vater: prognostic factors after curative surgery: a series of 45 cases. Gut 1997; 40:350-5.

14. Westgaard A, Tafjord S, Farstad IN, et al. Pancreatobiliary versus intestinal histologic type of differentiation is an independent prognostic factor in resected periampullary adenocarcinoma. BMC Cancer 2008;8:170.

15. Sessa F, Furlan D, Zampatti C, et al. Prognostic factors for ampullary adenocarcinomas: tumor stage, tumor histology, tumor location, immunohistochemistry and microsatellite instability. Virchows Arch 2007:451:649-57.

16. Park S, Kim SW, Kim SH, et al. Lack of microsatellite instability in neoplasms of ampulla of Vater. Pathol Int 2003;53:667-70.

17. Achille A, Biasi M0, Zamboni G, et al. Cancers of the papilla of Vater: mutator phenotype is associated with good prognosis. Clin Cancer Res 1997:3:1841-7.

18. Imai Y, Tsurutani $\mathrm{N}$, Oda $\mathrm{H}$, et al. Genetic instability and mutation of the TGF-betareceptor-II gene in ampullary carcinomas. Int J Cancer 1998;76:407-11.

19. Suto T, Habano W, Sugai $T$, et al. Infrequent microsatellite instability in biliary tract cancer. J Surg Oncol 2001;76:121-6.

20. Wang JC, Dick JE. Cancer stem cells: lessons from leukemia. Trends Cell Biol 2005; 15:494-501.

21. Reya T, Morrison SJ, Clarke MF, et al. Stem cells, cancer, and cancer stem cells Nature 2001;414:105-11.

22. Alison MR, Islam S. Attributes of adult stem cells. J Pathol 2009;217:144-60.

23. Lugli A, lezzi G, Hostettler I, et al. Prognostic impact of the expression of putative cancer stem cell markers CD133, CD166, CD44s, EpCAM, and ALDH1 in colorectal cancer. Br J Cancer 2010:103:382-90.

24. Mulder JW, Kruyt PM, Sewnath M, et al. Colorectal cancer prognosis and expression of exon-v6-containing CD44 proteins. Lancet 1994;344:1470-2.

25. Herrlich P, Pals S, Ponta H. CD44 in colon cancer. Eur J Cancer 1995;31:1110-12

26. Weg-Remers S, Anders M, von Lampe B, et al. Decreased expression of CD44 splicing variants in advanced colorectal carcinomas. Eur J Cancer 1998;34:1607-11.

27. O'Brien CA, Pollett A, Gallinger $S$, et al. A human colon cancer cell capable of initiating tumour growth in immunodeficient mice. Nature 2007;445:106-10. 
28. Ricci-Vitiani L, Lombardi DG, Pilozzi E, et al. Identification and expansion of human colon-cancer-initiating cells. Nature 2007:445:111-15.

29. Shmelkov SV, Butler JM, Hooper AT, et al. CD133 expression is not restricted to stem cells, and both CD133+ and CD133 - metastatic colon cancer cells initiate tumors. J Clin Invest 2008;118:2111-20.

30. Baumhoer D, Zlobec I, Tornillo L, et al. Immunophenotyping and oncogene amplifications in tumors of the papilla of Vater. Virchows Arch 2008;453:579-88.

31. Ruemmele P, Dietmaier W, Terracciano L, et al. Histopathologic features and microsatellite instability of cancers of the papilla of Vater and their precursor lesions. Am J Surg Pathol 2009;33:691-704.

32. Zlobec I, Steele R, Terracciano L, et al. Selecting immunohistochemical cut-off scores for novel biomarkers of progression and survival in colorectal cancer. J Clin Pathol 2007;60:1112-16.

33. Scarpa A, Di Pace C, Talamini G, et al. Cancer of the ampulla of Vater: chromosome 17p allelic loss is associated with poor prognosis. Gut 2000; 46:842-8.

34. Gires 0, Klein CA, Baeuerle PA. On the abundance of EpCAM on cancer stem cells. Nat Rev Cancer 2009;9:143.

35. Baeuerle PA, Gires 0. EpCAM (CD326) finding its role in cancer. Br J Cancer 2007:96:417-23.

36. van der Gun BT, Melchers LJ, Ruiters MH, et al. EpCAM in carcinogenesis: the good, the bad or the ugly. Carcinogenesis 2010;31:1913-21.

37. Spizzo G, Obrist P, Ensinger C, et al. Prognostic significance of Ep-CAM and Her-2/ neu overexpression in invasive breast cancer. Int J Cancer 2002;98:883-8.

38. Brunner A, Prelog M, Verdofer I, et al. EpCAM is predominantly expressed in high grade and advanced stage urothelial carcinoma of the bladder. J Clin Pathol 2008;61:307-10.

39. Prince S, Zeidman A, Dekel Y, et al. Expression of epithelial cell adhesion molecule in gallbladder carcinoma and its correlation with clinicopathological variables. $A m \mathrm{~J}$ Clin Pathol 2008;129:424-9.

40. Varga M, Obrist $\mathrm{P}$, Schneeberger $\mathrm{S}$, et al. Overexpression of epithelial cell adhesion molecule antigen in gallblader carcinoma is an independent marker for poor survival. Clin Cancer Res 2004;10:3131-6.

41. Stoecklein NH, Siegmund A, Scheunemann P, et al. Ep-CAM expression in squamous cell carcinoma of the esophagus: a potential therapeutic target and prognostic marker. BMC Cancer 2006;6:165.
42. Prang N, Preithner S, Brischwein K, et al. Cellular and complement-dependent cytotoxicity of Ep-CAM-specific monoclonal antibody MT201 against breast cancer cell lines. Br J Cancer 2005;92:342-9.

43. Mosolits S, Markovic K, Frödin JE, et al. Vaccination with Ep-CAM protein or antiidiotypic antibody induces Th1-biased response against MHC class I- and II-restricted Ep-CAM epitopes in colorectal carcinoma patients. Clin Cancer Res 2004; 10:5391-402

44. Scheunemann P, Stoecklein NH, Rehders A, et al. Frequency and prognostic significance of occult tumor cells in lymph nodes in patients with adenocarcinoma of the papilla of Vater. HPB (Oxford) 2007;9:135-9.

45. Fong $\mathbf{D}$, Steurer $\mathrm{M}$, Obrist $\mathrm{P}$, et al. Ep-CAM expression in pancreatic and ampullary carcinomas: frequency and prognostic relevance. J Clin Pathol 2008;61: $31-5$.

46. Maetzel D, Denzel S, Mack B, et al. Nuclear signalling by tumour-associated antigen EpCAM. Nat Cell Biol 2009;11:162-71.

47. Wielenga VJ, Smits R, Korinek V, et al. Expression of CD44 in Apc and Tcf mutant mice implies regulation by the WNT pathway. Am J Pathol 1999:154:515-23.

48. Hao J, Chen H, Madigan MC, et al. Co-expression of CD147 (EMMPRIN), CD44v3-10, MDR1 and monocarboxylate transporters is associated with prostate cancer drug resistance and progression. Br J Cancer 2010;103:1008-18.

49. Hsu KH, Tsai HW, Shan YS, et al. Significance of CD44 expression in gastrointestinal stromal tumors in relation to disease progression and survival. World J Surg 2007; 31:1438-44.

50. Lai CH, Shan YS, Sy ED, et al. The significance of CD44 expression in gastrointestinal neuroendocrine tumors. Hepatogastroenterology 2005;52:1071-6.

51. Weichert W, Knösel T, Bellach J, et al. ALCAM / D166 is overexpressed in colorectal carcinoma and correlates with shortened patient survival. J Clin Pathol 2004:57:1160-4

52. Kojima M, Ishii G, Atsumi N, et al. Immunohistochemical detection of CD133 expression in colorectal cancer: a clinicopathological study. Cancer Sci 2008:99:1578-83.

53. Horst D, Kriegl L, Engel J, et al. CD133 expression is an independent prognostic marker for low survival in colorectal cancer. Br J Cancer 2008;99:1285-9.

54. Salnikov AV, Gladkirch J, Moldenhauer G, et al. CD133 is indicative for a resistance phenotype but does not represent a prognostic marker for survival of non-small cell lung cancer patients. Int J Cancer 2010;126:950-8. 


\section{$\mathrm{JCP}$}

Effect of EpCAM, CD44, CD133 and CD166 expression on patient survival in tumours of the ampulla of Vater

Salvatore Piscuoglio, Frank S Lehmann, Inti Zlobec, Luigi Tornillo, Wolfgang Dietmaier, Arndt Hartmann, Peter H Wünsch, Fausto Sessa, Petra Rümmele, Daniel Baumhoer and Luigi M Terracciano

J Clin Pathol 2012 65: 140-145 originally published online November 30, 2011

doi: 10.1136/jclinpath-2011-200043

Updated information and services can be found at:

http://jcp.bmj.com/content/65/2/140

These include:

Supplementary Material

References

Email alerting service
Supplementary material can be found at:

http://jcp.bmj.com/content/suppl/2011/11/30/jclinpath-2011-200043.D C1

This article cites 51 articles, 9 of which you can access for free at: http://jcp.bmj.com/content/65/2/140\#BIBL

Receive free email alerts when new articles cite this article. Sign up in the box at the top right corner of the online article.

Topic
Collections

Articles on similar topics can be found in the following collections

Pancreas and biliary tract (157)

Immunology (including allergy) (1664)

Colon cancer (231)

\section{Notes}

To request permissions go to:

http://group.bmj.com/group/rights-licensing/permissions

To order reprints go to:

http://journals.bmj.com/cgi/reprintform

To subscribe to BMJ go to:

http://group.bmj.com/subscribe/ 